\title{
Correction: El-Sawah et al. Arbuscular Mycorrhizal Fungi and Plant Growth-Promoting Rhizobacteria Enhance Soil Key Enzymes, Plant Growth, Seed Yield, and Qualitative Attributes of Guar. Agriculture 2021, 11, 194
}

\author{
Ahmed M. El-Sawah ${ }^{1}{ }^{(D}$, Ali El-Keblawy ${ }^{2}{ }^{D}$, Dina Fathi Ismail Ali ${ }^{1}{ }^{D}$, Heba M. Ibrahim $^{3}$, \\ Mohamed A. El-Sheikh ${ }^{4}\left(\mathbb{D}\right.$, Anket Sharma ${ }^{5}$ D , Yousef Alhaj Hamoud ${ }^{6}$, Hiba Shaghaleh ${ }^{7}$, Marian Brestic $^{8,9}{ }^{\mathbb{D}}$, \\ Milan Skalicky ${ }^{8}\left(\mathbb{D}\right.$, You-Cai Xiong ${ }^{10, *(D)}$ and Mohamed S. Sheteiwy ${ }^{11, *(D)}$
}

check for updates

Citation: El-Sawah, A.M. El-Keblawy, A.; Ali, D.F.I.; Ibrahim, H.M.; El-Sheikh, M.A.; Sharma, A.; Alhaj Hamoud, Y.; Shaghaleh, H.; Brestic, M.; Skalicky, M.; et al. Correction: El-Sawah et al.

Arbuscular Mycorrhizal Fungi and Plant Growth-Promoting Rhizobacteria Enhance Soil Key Enzymes, Plant Growth, Seed Yield, and Qualitative Attributes of Guar. Agriculture 2021, 11, 194. Agriculture 2021, 11, 1033

https://doi.org/10.3390/

agriculture11111033

Received: 15 October 2021

Accepted: 18 October 2021

Published: 21 October 2021

Publisher's Note: MDPI stays neutral with regard to jurisdictional claims in published maps and institutional affiliations.

Copyright: (c) 2021 by the authors. Licensee MDPI, Basel, Switzerland. This article is an open access article distributed under the terms and conditions of the Creative Commons Attribution (CC BY) license (https:// creativecommons.org/licenses/by/ $4.0 /)$
1 Department of Agricultural Microbiology, Faculty of Agriculture, Mansoura University, Mansoura 35516, Egypt; ahmedelsawah89@mans.edu.eg (A.M.E.-S.); dfali@mans.edu.eg (D.F.I.A.)

2 Department of Applied Biology, Faculty of Science, University of Sharjah, Sharjah P.O. Box 27272, United Arab Emirates; akeblawy@sharjah.ac.ae

3 Department of Botany, Faculty of Agriculture, Mansoura University, Mansoura 35516, Egypt; hebaho@mans.edu.eg

4 Botany and Microbiology Department, College of Science, King Saud University, P.O. Box 2455, Riyadh 11451, Saudi Arabia; melsheikh@ksu.edu.sa

5 State Key Laboratory of Silviculture, Zhejiang A\&F University, Hangzhou 311300, China; anketsharma@gmail.com

6 College of Agricultural Science and Engineering, Hohai University, Nanjing 210098, China; yousef-hamoud11@hotmail.com

7 Jiangsu Provincial Key Lab for the Chemistry and Utilization of Agro-Forest Biomass, College of Chemical Engineering, Nanjing Forestry University, Nanjing 210037, China; hiba-shaghaleh@hotmail.com

8 Department of Botany and Plant Physiology, Faculty of Agrobiology, Food and Natural Resources, Czech University of Life Sciences Prague, Kamycka 129, 16500 Prague, Czech Republic; marian.brestic@uniag.sk (M.B.); skalicky@af.czu.cz (M.S.)

9 Department of Plant Physiology, Slovak University of Agriculture, 94911 Nitra, Slovakia

10 State Key Laboratory of Grassland Agro-Ecosystems, Institute of Arid Agroecology, School of Life Sciences, Lanzhou University, Lanzhou 730000, China

11 Department of Agronomy, Faculty of Agriculture, Mansoura University, Mansoura 35516, Egypt

* Correspondence: xiongyc@lzu.edu.cn (Y.-C.X.); salahco_2010@mans.edu.eg (M.S.S.)

\section{Figure Legend}

In the original article [1], there was a mistake in the legend for Figure 5. Relationship between the mean phosphatase activity and branch/plant (A), guaran (C), and seed yield (E), and the mean dehydrogenase activity and branch/plant (B), guaran (D), and seed yield (F) in soybean treated with arbuscular mycorrhizal fungi and plant growth-promoting rhizobacteria. $p \geq 0.01$ ( ${ }^{*}$ significant). The correct legend appears below. The authors apologize for any inconvenience caused and state that the scientific conclusions are unaffected. The original article has been updated.

Figure 5. Relationship between the mean phosphatase activity and branch/plant (A), guaran (C), and seed yield (E), and the mean dehydrogenase activity and branch/plant (B), guaran (D), and seed yield (F) in guar treated with arbuscular mycorrhizal fungi and plant growth-promoting rhizobacteria. $p \geq 0.01$ (* significant).

In the original article, there was a mistake in the legend for Figure 6. Relationship between the mean protease activity and branch/plant (A), guaran (C), and seed yield (E), and the mean invertase activity and branch/plant (B), guaran (D), and seed yield (F), in soybean treated with arbuscular mycorrhizal fungi and plant growth-promoting rhizobacteria. $p \geq 0.01$ ( ${ }^{*}$ significant). The correct legend appears below. The authors apologize for any inconvenience caused and state that the scientific conclusions are unaffected. The original article has been updated. 
Figure 6. Relationship between the mean protease activity and branch/plant (A), guaran (C), and seed yield (E), and the mean invertase activity and branch/plant (B), guaran (D), and seed yield (F), in guar treated with arbuscular mycorrhizal fungi and plant growth-promoting rhizobacteria. $p \geq 0.01$ ( ${ }^{*}$ significant).

\section{Text Correction}

There was an error in the original article. The correlation analysis showed that the number of branches of soybean was positively correlated with both dehydrogenase and phosphatase activities (Figure 5A,B) and a similar relationship was also observed with protease and invertase activities (Figure 6A,B), while these enzymes negatively correlated with the guaran content (Figures $5 \mathrm{C}, \mathrm{D}$ and $6 \mathrm{C}, \mathrm{D}$ ).

A correction has been made to 3. Results, 3.6. Effects of Biofertilizers on Enzyme Activities in the Rhizosphere of the Guar Plant, the 2nd paragraph:

The correlation analysis showed that the number of branches of guar was positively correlated with both dehydrogenase and phosphatase activities (Figure 5A,B) and a similar relationship was also observed with protease and invertase activities (Figure 6A,B), while these enzymes negatively correlated with guaran content (Figures 5C,D and 6C,D). In addition, the correlation analysis showed a significant correlation between the activities of both dehydrogenase and invertase with seed yield (Figures 5E and 6E), and there was a negative correlation in the case of phosphatase and protease activities with seed yield (Figures 5F and 6F).

The authors apologize for any inconvenience caused and state that the scientific conclusions are unaffected. The original article has been updated.

\section{Reference}

1. El-Sawah, A.M.; El-Keblawy, A.; Ali, D.F.I; Ibrahim, H.M.; El-Sheikh, M.A.; Sharma, A.; Alhaj Hamoud, Y.; Shaghaleh, H.; Brestic, M.; Skalicky, M.; et al. Arbuscular Mycorrhizal Fungi and Plant Growth-Promoting Rhizobacteria Enhance Soil Key Enzymes, Plant Growth, Seed Yield, and Qualitative Attributes of Guar. Agriculture 2021, 11, 194. [CrossRef] 